\title{
Clinical and economic burden of dyspnea and other COPD symptoms in a managed care setting
}

\author{
This article was published in the following Dove Press journal: \\ International Journal of COPD \\ 4 July 2017 \\ Number of times this article has been viewed
}

\section{Judith J Stephenson' \\ Debra Wertz' \\ Tao Gu' \\ Jeetvan Patel ${ }^{2}$ \\ Anand A Dalal ${ }^{2}$}

'HealthCore, Inc., Wilmington, DE, ${ }^{2}$ GlaxoSmithKline, Research Triangle Park, NC, USA
Correspondence: Judith J Stephenson HealthCore, Inc., 123 Justison Street, Suite 200, Wilmington, DE 1980I, USA $\mathrm{Tel}+\mathrm{I} 3022302142$

Fax +l 3022302020

Email jstephenson@healthcore.com
Purpose: The degree to which symptoms such as dyspnea affect patients with COPD is individualized. To address the gap between clinical symptom measures and self-perceived disease burden, we investigated the symptom status of adult patients with COPD and followed with an administrative claims analysis of health care resource utilization and costs.

Methods: This was a hybrid US observational study consisting of a cross-sectional patient survey followed by a retrospective analysis of administrative claims data. The primary COPD symptom measures were the modified Medical Research Council (mMRC) Dyspnea scale and the COPD Assessment Test (CAT).

Results: A total of 673 patients completed the survey. Of these, $65 \%$ reported mMRC grades 0-1 (low symptomatology) and 35\% reported mMRC grades 2-4 (high symptomatology); $25 \%$ reported CAT score $<10$ (low symptomatology) and $75 \%$ reported CAT score $\geq 10$ (high symptomatology). More patients with high symptomatology (by either measure) had at least one COPD-related inpatient hospitalization, emergency room visit, physician office visit, or other outpatient services, and filled at least one COPD-related prescription medication vs patients with low symptomatology. COPD-related costs were higher for patients with high symptomatology than patients with low symptomatology. In a multivariate analysis, COPD-related costs were also higher in patients reporting severe symptoms.

Conclusion: Patients with high COPD symptomatology utilized more health care resources and had higher COPD-related health care costs during the 6-month post-survey period than patients with low symptomatology.

Keywords: COPD, dyspnea, health status, symptoms, health care resource utilization, health care costs

\section{Introduction}

COPD encompasses a group of preventable respiratory diseases characterized by progressive airflow limitation that is not fully reversible. Symptoms of COPD include chronic cough, exertional dyspnea, expectoration, and wheeze. COPD is also characterized by exacerbations, defined as a worsening of a patient's respiratory symptoms beyond those expected of normal day-to-day variations, with acute onset, and warranting adjustment of medication. ${ }^{1}$

The current treatment objectives for stable COPD fall under two categories: relieving and reducing the impact of symptoms, and reducing the risk of adverse health events such as exacerbations, which may affect the patient at a later date. The goal of COPD exacerbation treatment is to minimize the impact of the current exacerbation and to prevent the development of subsequent exacerbations. ${ }^{1}$ However, guidelines are inconsistently followed and patients may not be treated appropriately. ${ }^{2}$ 
Previous research has found that moderate-to-severe exacerbations that require hospitalizations and emergency room (ER) visits are major cost drivers in COPD ${ }^{3-5}$ In the Global Initiative for Chronic Obstructive Lung Disease (GOLD) consensus report, it is recommended that COPD is assessed based on the patient's symptom level, future risk of exacerbations, comorbidities, and severity of airflow limitation. ${ }^{1}$ Airflow limitation is divided into four severity categories (mild to very severe) based on forced expiratory volume in 1 second. While such a measure may overdiagnose COPD in some elderly patients with normal age-related changes in lung volume, it may also underdiagnose the condition in patients younger than 45 years. ${ }^{6}$ Furthermore, the degree to which a patient is affected by symptoms, particularly dyspnea, is individualized. ${ }^{7}$ That is, a level of dyspnea rated as clinically mild may be troublesome to a specific patient, causing patient perception of the condition to be more severe.

To address the gap between clinical symptom measures and patient self-perceived disease burden, we investigated the COPD symptom status of patients and followed with a claims analysis of their health care resource utilization and costs. The aims of this study were to assess patient-reported dyspnea and other COPD symptoms and to determine their association with estimated health care resource utilization and direct costs using administrative claims data.

\section{Methods}

\section{Study design}

This was a two-part observational study conducted in the US consisting of a cross-sectional patient survey of adults with COPD followed by a retrospective analysis of patients' administrative claims data.

After completion of the patient surveys that were conducted between October 2011 and January 2012, and after sufficient time had elapsed for full claims capture and adjudication, a database was created consisting of survey respondents' administrative claims data for the 6-month periods before and after the survey date. A patient-level analytic file for the 6-month preand post-survey periods was created and merged with the survey data for analyses of the resource utilization and direct health care costs of survey respondents. The claims analyses occurred after sufficient time had elapsed for full claims adjudication, such that there were administrative claims for the 6-month periods prior to and following the patient survey date.

\section{Patients}

The patient survey sample was identified from the HealthCore Integrated Research Database (HIRD), an integrated, de-identified US administrative claims database. The HIRD contains eligibility, medical, and pharmacy claims for approximately 44 million members of 14 commercial health insurance plans across the US. Patients were selected for the survey based on claims submitted from February 1, 2010, to January 31, 2011 (the patient sample list identification period). Eligible patients were aged $\geq 40$ years at the date of the last COPD medical claim within the identification period (the COPD index date), with two or more medical claims with an International Classification of Diseases-Ninth RevisionClinical Modification (ICD-9-CM) diagnosis code for COPD on different dates of service during the identification period.

Patients were excluded from the study if they had at least one claim during the patient list identification period with an ICD-9-CM diagnosis code for cystic fibrosis, respiratory cancer, pulmonary fibrosis, pneumoconiosis, sarcoidosis, or pulmonary tuberculosis. Additional eligibility and exclusion criteria are included in Supplementary material.

Assessment of data from the HIRD complied with federal and state laws and regulations, including those related to privacy and security of individually identifiable health information. The study protocol and all other patient-related materials were approved by the New England Institutional Review Board. All survey respondents gave full informed verbal consent prior to the survey.

\section{Patient survey}

\section{Survey administration}

Prenotification letters were sent inviting eligible patients to participate in the study and requesting them to either opt-in or opt-out by telephone. Patients who did not respond to the prenotification letter were contacted by telephone by trained interviewers. Patients who gave verbal consent to participate in the study had the option of completing the one-time survey either by telephone interview or online.

\section{Survey measures}

The primary COPD symptom measures were the modified Medical Research Council (mMRC) Dyspnea scale ${ }^{8-10}$ and the COPD Assessment Test (CAT). ${ }^{11}$ Additional secondary measures included the Work Productivity and Activity Impairment (WPAI) scale, ${ }^{12,13}$ the Clinical COPD Questionnaire (CCQ), ${ }^{14,15}$ and the Duke Health Profile (DUKE). ${ }^{16}$

To simplify the analysis and following GOLD recommendations, mMRC and CAT scores were each grouped into two categories of low and high symptomatology:

- mMRC grades 0-1 were classified as low dyspnea symptomatology.

- mMRC grades 2-4 were classified as high dyspnea symptomatology. 
- CAT scores 0-9 were classified as low COPD symptomatology.

- CAT scores 10-40 were classified as high COPD symptomatology.

Further details of additional secondary measures and other variables can be found in Supplementary material.

\section{Administrative claims analysis}

Administrative claims submitted 6 months prior to and following the survey date were extracted from the HIRD for patients who had completed the patient survey. Patient demographics, as well as clinical characteristics (Deyo-Charlson Comorbidity Index [DCI] score ${ }^{17}$ and comorbidities, medications administered, and dyspnea and asthma flags), were assessed using the claims data. In addition, COPD-related health care resource utilization and costs were assessed for the 6-month period prior to and following the survey date. Unique patient identification numbers linked the survey and claims data, and the merged survey/claims data were used for the study analyses.

\section{Statistical analysis}

For descriptive analyses, mean, standard deviation (SD), and median were reported for continuous variables. Frequency and percentages were reported for categorical variables. Statistical comparisons between symptom cohorts used bivariate or unadjusted comparisons, in which continuous characteristics were compared using two-sample $t$-tests and categorical variables were compared using chi-square tests, and used multivariate regression models to determine statistically significant differences in outcomes while adjusting for potential confounding variables. Generalized linear models with a logarithmic link function and gamma distribution determined COPD-related 6-month post-survey period cost drivers. All post-period cost models controlled for pre-survey covariates, including dyspnea and COPD symptom status, age, sex, smoking status, employment status, body mass index (BMI), DCI score, number of COPD maintenance therapy drug classes, home oxygen therapy use, and presence of COPD exacerbations.

All costs are reported in 2012 US dollars. All analyses were conducted using SAS version 9.2 (SAS Institute Inc., Cary, NC, USA). An a priori $\alpha$-level of $P \leq 0.05$ was considered significant.

\section{Results}

\section{Patient disposition}

Of the 8,500 patients on the patient list, 860 patients completed the survey and 2,506 patients refused the survey. The remaining 5,134 patients were not contacted due to incorrect contact information, because the maximum number of contact attempts had been reached, or because the target number of completed surveys had been obtained and the survey closed (Figure 1). After merging the survey data of the 860 respondents with their claims data for the 6-month periods prior to and following the survey date, 693 respondents had at least 6 months of eligibility and claims prior to and following the survey date. Of these people, 673 patients had valid mMRC scores and comprised the study population (Figure 1).

Patient demographics for the study population $(\mathrm{N}=673)$ are given in Table 1. There were slightly more females $(57.8 \%)$ and almost half of the population (47.9\%) were aged 56-64 years. A large proportion of the population were located in the Midwest (43.8\%), and the majority were enrolled in a preferred provider organization (PPO) health plan (64.6\%). Approximately half of the population had at least one medical claim for dyspnea during the 12-month patient identification period and the mean (SD) DCI score was 2.65 (2.22).

\section{Patient survey results: COPD symptom analyses mMRC Dyspnea scale}

Among the 673 patients, $65 \%$ reported mMRC grades 0 or 1 , considered mMRC low dyspnea symptomatology and $35 \%$ reported $\mathrm{mMRC}$ grades $2-4$, considered $\mathrm{mMRC}$ high dyspnea symptomatology (Figure 2A).

Significant differences between patients with low and high mMRC symptomatology were observed in terms of COPD diagnosis, obesity, employment status, household income, self-reported peripheral vascular disease, and diabetes complications (Table 2). No differences between groups were observed for sex, age at the time of the survey, race, educational status, or smoking status.

Compared with patients with low dyspnea symptoms, a significantly higher percentage of patients with high dyspnea symptoms reported that a physician had told them they had COPD (88.1\% vs 69.8\%; $P<0.0001$; Table 2), were diagnosed with COPD at a younger age (52.4 vs 55.2 years; $P=0.001$; Table 2), and had a longer history of COPD (7.1 years vs 5.0 years; $P=0.001$; Table 2 ). Slightly more patients in the high mMRC group had a spirometry test in the last 6 months compared with the low mMRC group (44.5\% vs $39.4 \% ; P=0.342$; Table 2 ). Compared with patients with low dyspnea symptoms, a significantly higher percentage of patients with high symptoms were not working $(60.2 \%$ vs $33.0 \% ; P<0.0001$; Table 2), reported a 2010 household income of $<\$ 50,000$ (61.4\% vs $53.6 \% ; P=0.012$; Table 2$)$, 


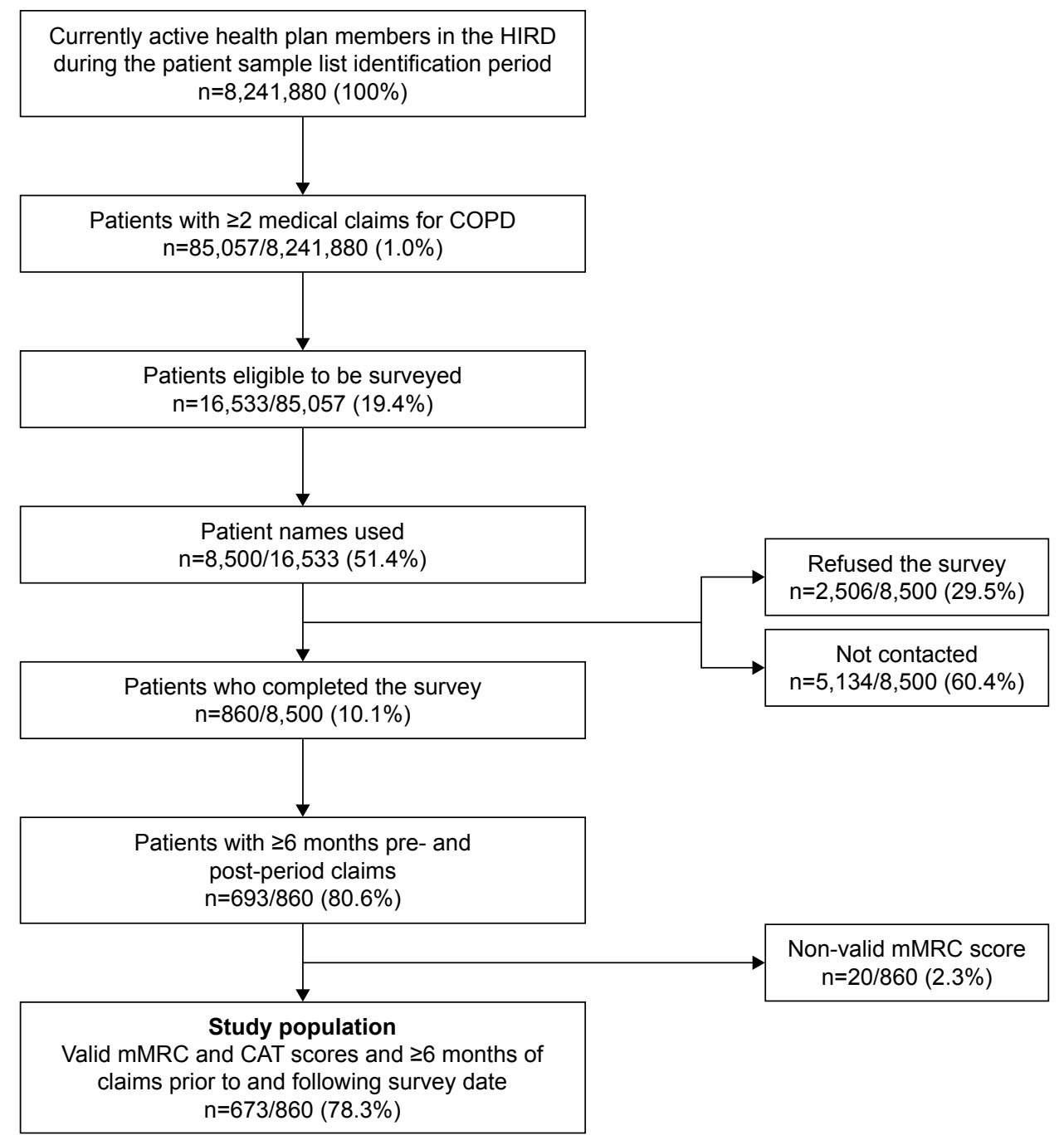

Figure I Sample disposition.

Abbreviations: CAT, COPD Assessment Test; HIRD, HealthCore Integrated Research Database; mMRC, modified Medical Research Council.

were obese (BMI $>29.9 ; 48.3 \%$ vs $35.7 \% ; P=0.003$; Table 2 ), reported peripheral vascular disease $(27.5 \%$ vs $11.2 \%$; $P<0.0001$; Table 2), and reported diabetes complications ( $8.5 \%$ vs $4.4 \% ; P=0.029$; Table 2 ).

\section{COPD Assessment Test}

Among the 673 patients, $25 \%$ reported CAT scores $<10$, considered low CAT COPD symptomatology and 75\% reported CAT scores $\geq 10$, considered high CAT COPD symptomatology (Figure 2B).

Significant differences between patients with low and high CAT COPD symptomatology were observed in terms of sex, COPD diagnosis, educational status, employment status, household income, hypertension, diabetes, peripheral vascular disease, heart attack, stroke, and a spirometry test in the last 6 months (Table 3). No differences between groups were observed for age at the time of the survey, COPD duration, BMI, race, or smoking status.

Compared with low CAT COPD symptom patients, a significantly higher percentage of patients with high CAT COPD symptoms reported that a physician had told them they had COPD (83.2\% vs $55.9 \% ; P<0.0001$; Table 3 ), were diagnosed with COPD at a younger age (53.7 vs 55.9 years; $P=0.047$; Table 3$)$, were female $(60.3 \%$ vs $50.3 \%$; $P=0.024$; Table 3$)$, were not working $(46.4 \%$ vs $30.5 \%$; $P=0.001$; Table 3), were less likely to be a college graduate (33.4\% vs $43.1 \% ; P=0.039$; Table 3 ), and reported a 2010 household income of $<\$ 50,000$ (59.1\% vs $47.1 \%$; $P=0.015$; Table 3). More patients in the high CAT COPD symptom group had a spirometry test in the last 6 months $(44.1 \%$ vs $32.3 \%$; $P=0.027$; Table 3 ), reported having hypertension, diabetes, peripheral vascular disease, heart attack, and stroke compared with the low CAT COPD symptom group. 
Table I Patient sample demographics

\begin{tabular}{ll}
\hline Characteristics & $\begin{array}{l}\text { Population } \\
(\mathbf{n}=673)\end{array}$ \\
\hline Female (n, \%) & $389(57.8)$ \\
Age, years (n, \%) & \\
$\quad 40-55$ & $234(34.8)$ \\
$56-64$ & $322(47.9)$ \\
$\geq 65$ & $117(17.4)$ \\
Health plan region (n, \%) & \\
Northeast & $96(14.3)$ \\
Midwest & $295(43.8)$ \\
South & $196(29.1)$ \\
West & $86(12.8)$ \\
Health plan type (n, \%) & \\
PPO & $435(64.6)$ \\
Other & $238(35.4)$ \\
Dyspnea claim ${ }^{\text {a }}(\mathrm{n}, \%)$ & $330(49.0)$ \\
DCl score ${ }^{\mathrm{b}}($ mean, SD) & $2.65(2.22)$ \\
\hline
\end{tabular}

Notes: aDyspnea claim is "yes" if a patient had at least one medical claim for dyspnea during the 12-month patient identification period, otherwise dyspnea claim is "no." ${ }^{b} \mathrm{DCl}$ calculated from claims during the 12-month patient identification period. Abbreviations: DCl, Deyo-Charlson Comorbidity Index; PPO, preferred provider organization; SD, standard deviation.

\section{Health care resource utilization and costs}

During the 6-month post-survey period, patients with high COPD symptomatology (mMRC scores $\geq 2$ or CAT scores $\geq 10$ ) utilized more health care resources than patients with low mMRC or CAT scores (Figure 3A). Compared with patients with low COPD symptomatology, a significantly greater percentage of patients with high symptomatology had at least one COPD-related inpatient hospitalization, ER visit, physician office visit, other outpatient service, and filled at least one COPD-related prescription medication.

COPD-related health care costs during the 6-month post-survey period were also higher among patients with more severe COPD symptoms (Figure 3B). Inpatient costs were markedly higher for patients with more severe symptoms compared with patients with less severe symptoms
(mMRC: $\$ 2,584$ vs $\$ 1,032, P=0.041$; CAT: $\$ 2,006$ vs $\$ 273$, $P<0.001)$.

\section{Multivariate analyses}

Multivariate analyses to determine the drivers of COPDrelated costs during the 6-month post-survey period found that after controlling for all other covariates in the model, the estimated COPD-related total costs of patients with high dyspnea symptoms were $46 \%$ higher $(P=0.025)$ than for patients with low dyspnea symptoms (Figure 4A). Similarly, the estimated COPD-related total costs of patients with high CAT COPD symptoms were $51 \%$ higher than for patients with low CAT COPD symptoms, although this result was not statistically significant (Figure 4B).

COPD-related costs were higher for patients with high dyspnea symptomatology than those with low dyspnea symptomatology for both unadjusted $(\$ 2,003$ higher; $P=0.015)$ and adjusted costs $(\$ 1,769$ higher; $P=0.025$; Figure 5). COPD-related costs were also higher among patients with high COPD symptomatology as measured by CAT scores vs low COPD symptomatology for both unadjusted $(\$ 2,707$ higher; $P<0.0001)$ and adjusted $(\$ 1,769$; $P=0.057$ ) COPD-related costs (Figure 5); although after controlling for covariates, the difference was no longer significant. The primary cost driver of both unadjusted and adjusted COPD-related costs was predominantly patient hospitalization costs; although for unadjusted low CAT COPD symptomatology patients, the split between medical and pharmacy costs was approximately even.

\section{Patient-reported outcomes (survey)}

Significant differences were observed in all patient-reported outcome instrument scale/subscale scores for patients with high symptomatology compared with those with low symptomatology (all $P$-values of $<0.0001$, except absenteeism

\section{A}

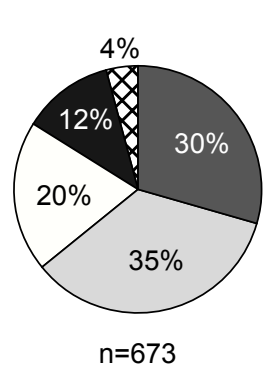

0: Breathless with strenuous exercise

$\square$ 1: Breathless when walking up a slight hill

$\square$ 2: Walk slower than people of the same age due to breathlessness

3: Breathless after walking about $100 \mathrm{~m}$

4: Too breathless to leave the house

\section{B CAT responses}

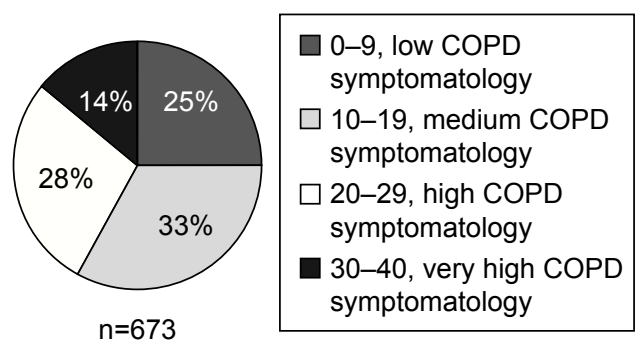

Figure 2 Patient survey COPD symptom results from the (A) mMRC Dyspnea scale and (B) CAT ${ }^{\mathrm{a}}$.

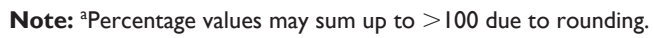

Abbreviations: CAT, COPD Assessment Test; mMRC, modified Medical Research Council. 
Table 2 Self-reported patient characteristics by mMRC Dyspnea scale category

\begin{tabular}{|c|c|c|c|}
\hline Characteristics & $\begin{array}{l}\text { Low mMRC } \\
\text { symptomatology } \\
\text { (grades } 0-I)(n=437)\end{array}$ & $\begin{array}{l}\text { High mMRC } \\
\text { symptomatology } \\
\text { (grades } 2-4)(n=236)\end{array}$ & $P$-value \\
\hline \multicolumn{4}{|l|}{ Sex, n (\%) } \\
\hline Male & $190(43.5)$ & $94(39.8)$ & 0.361 \\
\hline Female & $247(56.5)$ & $142(60.2)$ & \\
\hline Age at survey (year), mean (SD) & $58.8(8.1)$ & $58.9(8.6)$ & 0.850 \\
\hline Age at COPD diagnosis (year), mean (SD) & $55.2(8.7)$ & $52.4(9.5)$ & 0.001 \\
\hline Years since COPD diagnosis, mean (SD) & $5.0(5.4)$ & 7.1 (7.7) & 0.001 \\
\hline Told by physician that they had COPD, $\mathrm{n}(\%)$ & $305(69.8)$ & $208(88.1)$ & $<0.0001$ \\
\hline \multicolumn{4}{|l|}{ BMI $\left(\mathrm{kg} / \mathrm{m}^{2}\right), \mathrm{n}(\%)$} \\
\hline Obese (BMI > 29.9) & $156(35.7)$ & II 4 (48.3) & \\
\hline Overweight (BMI 25.0-29.9) & $145(33.2)$ & $54(22.9)$ & 0.003 \\
\hline Normal/underweight $(\mathrm{BMI}<25.0)$ & $136(31.1)$ & $68(28.8)$ & \\
\hline \multicolumn{4}{|l|}{ Combined race/ethnicity, n (\%) } \\
\hline White/Caucasian & $395(90.4)$ & $212(89.8)$ & 0.647 \\
\hline Other & $42(9.6)$ & $24(10.2)$ & \\
\hline \multicolumn{4}{|l|}{ Educational status, n (\%) } \\
\hline High school or less & $186(42.6)$ & II 5 (48.7) & 0.145 \\
\hline Some college, but no degree & $83(19.0)$ & $48(20.3)$ & \\
\hline Two-year degree or over & $168(38.4)$ & $73(30.9)$ & \\
\hline \multicolumn{4}{|l|}{ Employment status, n (\%) } \\
\hline Employed full time & $238(54.5)$ & $76(32.2)$ & $<0.0001$ \\
\hline Employed part time & $55(12.6)$ & $18(7.6)$ & \\
\hline Not working & I $44(33.0)$ & $142(60.2)$ & \\
\hline \multicolumn{4}{|l|}{2010 household income, $\mathrm{n}(\%)$} \\
\hline$<\$ 50,000$ & $234(53.6)$ & $145(6 \mid .4)$ & 0.012 \\
\hline$\$ 50,000-\$ 99,999$ & $152(34.8)$ & $79(33.5)$ & \\
\hline$\geq \$ 100,000$ & $5 I(I I .7)$ & $12(5.1)$ & \\
\hline \multicolumn{4}{|l|}{ Smoking status, n (\%) } \\
\hline Current smoker & $163(37.3)$ & $88(37.3)$ & 0.471 \\
\hline Former smoker & $216(49.4)$ & $124(52.5)$ & \\
\hline Never smoked & $58(\mid 3.3)$ & $24(10.2)$ & \\
\hline \multicolumn{4}{|l|}{ Conditions, n (\%) } \\
\hline Hypercholesterolemia & $214(49.0)$ & $125(53.0)$ & 0.323 \\
\hline Hypertension & $217(49.7)$ & $133(56.4)$ & 0.097 \\
\hline Diabetes & $81(18.5)$ & $56(23.7)$ & 0.110 \\
\hline Peripheral vascular disease & 49 (1I.2) & $65(27.5)$ & $<0.000$ I \\
\hline Heart attack & $47(10.8)$ & $37(15.7)$ & 0.065 \\
\hline Stroke & $28(6.4)$ & $21(8.9)$ & 0.235 \\
\hline Diabetes complications & $19(4.4)$ & $20(8.5)$ & 0.029 \\
\hline Hardening of the arteries & $27(6.2)$ & $16(6.8)$ & 0.231 \\
\hline \multicolumn{4}{|l|}{ Spirometry, n (\%) } \\
\hline Spirometry test in the 6 months prior to the survey & $172(39.4)$ & $105(44.5)$ & 0.342 \\
\hline
\end{tabular}

Abbreviations: BMI, body mass index; mMRC, modified Medical Research Council; SD, standard deviation.

$P=0.008$; further results are given in Supplementary material).

\section{Discussion}

Patients with all severities of COPD are affected by dyspnea, either at rest or during exercise. ${ }^{18}$ Dyspnea is highly prevalent in patients with COPD ranging from $39.5 \%$ to $60.2 \%$ in Europe $^{19}$ and $70 \%$ in the $\mathrm{USA}^{18}$ and is a major cause of disability and anxiety. ${ }^{1}$ Moderate-to-severe dyspnea is associated with a more frequent incidence of exacerbations and a poorer health status and quality of life. ${ }^{19}$ COPD symptoms, including dyspnea, contribute to disease severity, ${ }^{18}$ and reducing symptoms, as well as improving health status and reducing the risk of exacerbations, are important goals for the treatment of COPD. ${ }^{1}$

In this real-world, observational study, we assessed patient perceptions of dyspnea and COPD symptomatology and linked those data to claims data to assess health care 
Table 3 Self-reported patient characteristics by CAT COPD symptom category

\begin{tabular}{|c|c|c|c|}
\hline Characteristics & $\begin{array}{l}\text { Low CAT } \\
\text { symptomatology } \\
(\text { score }<10)(n=167)\end{array}$ & $\begin{array}{l}\text { High CAT } \\
\text { symptomatology } \\
(\text { score } \geq 10)(n=506)\end{array}$ & $P$-value \\
\hline \multicolumn{4}{|l|}{ Sex, n (\%) } \\
\hline Male & $83(49.7)$ & 201 (39.7) & 0.024 \\
\hline Female & $84(50.3)$ & $305(60.3)$ & \\
\hline Age at survey (year), mean (SD) & $58.5(7.6)$ & $58.9(8.5)$ & 0.546 \\
\hline Age at COPD diagnosis (year), mean (SD) & $55.9(8.2)$ & $53.7(9.3)$ & 0.047 \\
\hline Years since COPD diagnosis, mean (SD) & $5.3(5.9)$ & $6.0(6.6)$ & $0.24 I$ \\
\hline Told by physician that they had COPD, $\mathrm{n}(\%)$ & $92(55.1)$ & $421(83.2)$ & $<0.000 \mathrm{I}$ \\
\hline \multicolumn{4}{|l|}{ BMI $\left(\mathrm{kg} / \mathrm{m}^{2}\right), \mathrm{n}(\%)$} \\
\hline Obese (BMI > 29.9) & $58(34.7)$ & $212(4 \mid .9)$ & \\
\hline Overweight (BMI 25.0-29.9) & $52(31.1)$ & $147(29.1)$ & 0.231 \\
\hline Normal/underweight $(\mathrm{BMI}<25.0$ ) & $57(34.1)$ & $147(29.1)$ & \\
\hline \multicolumn{4}{|l|}{ Combined race/ethnicity, n (\%) } \\
\hline White/Caucasian & $149(89.2)$ & $458(90.5)$ & 0.956 \\
\hline Other & $18(10.8)$ & $48(9.5)$ & \\
\hline \multicolumn{4}{|l|}{ Educational status, n (\%) } \\
\hline High school or less & $71(42.5)$ & $230(45.5)$ & \\
\hline Some college, but no degree & $24(14.4)$ & $107(2 \mid .2)$ & 0.039 \\
\hline Two-year degree or over & $72(43.1)$ & $169(33.4)$ & \\
\hline \multicolumn{4}{|l|}{ Employment status, n (\%) } \\
\hline Employed full time & $97(58.1)$ & $217(42.9)$ & 0.001 \\
\hline Employed part time & $19(11.4)$ & $54(19.7)$ & \\
\hline Not working & $5 \mathrm{I}(30.5)$ & $235(46.4)$ & \\
\hline \multicolumn{4}{|l|}{2010 household income, $\mathrm{n}(\%)$} \\
\hline$<\$ 50,000$ & $80(47.9)$ & $299(59.1)$ & 0.015 \\
\hline$\$ 50,000-\$ 99,999$ & $64(38.3)$ & $167(33.0)$ & \\
\hline$\geq \$ 100,000$ & $23(13.8)$ & $40(7.9)$ & \\
\hline \multicolumn{4}{|l|}{ Smoking status, n (\%) } \\
\hline Current smoker & $52(31.1)$ & $199(39.3)$ & 0.069 \\
\hline Former smoker & $88(52.7)$ & $252(49.8)$ & \\
\hline Never smoked & $27(16.1)$ & $55(10.9)$ & \\
\hline \multicolumn{4}{|l|}{ Conditions, n (\%) } \\
\hline Hypercholesterolemia & $81(48.5)$ & $258(51.0)$ & 0.578 \\
\hline Hypertension & $75(44.9)$ & $275(54.4)$ & 0.034 \\
\hline Diabetes & $24(14.4)$ & II3 (23.3) & 0.027 \\
\hline Peripheral vascular disease & $15(9.0)$ & $99(19.6)$ & 0.002 \\
\hline Heart attack & II (6.6) & $73(14.4)$ & 0.008 \\
\hline Stroke & $4(2.4)$ & $45(8.9)$ & 0.005 \\
\hline Diabetes complications & $6(3.6)$ & $33(6.5)$ & 0.160 \\
\hline Hardening of the arteries & $7(4.2)$ & $36(7.1)$ & 0.181 \\
\hline \multicolumn{4}{|l|}{ Spirometry, n (\%) } \\
\hline Spirometry test in the 6 months prior to the survey & $54(32.3)$ & $223(44.1)$ & 0.027 \\
\hline
\end{tabular}

Abbreviations: BMI, body mass index; CAT, COPD Assessment Test; SD, standard deviation.

resource utilization and costs in the US. We found that patients who rated their dyspnea as more severe (with high mMRC scores $[\geq 2]$ ) or with higher health status impairment (high CAT scores $[\geq 10]$ ) used more health care resources and incurred higher treatment costs than patients who rated their condition as less severe. This was primarily driven by medical costs vs pharmacy costs. As such, these data show that COPD symptoms have a noticeable impact on health care resource utilization and costs. When unadjusted costs were used for the analyses, the cost associated with patients with severe symptoms was greater when assessed using the CAT compared with the mMRC Dyspnea test. However, there was only a significant difference in adjusted costs for patients categorized by mMRC. It is unclear why the cost difference was not significant with CAT; however, this may be due to the multidimensional nature of the CAT, which assesses symptoms and health status, whereas the mMRC scale measures dyspnea only. It has been reported previously 


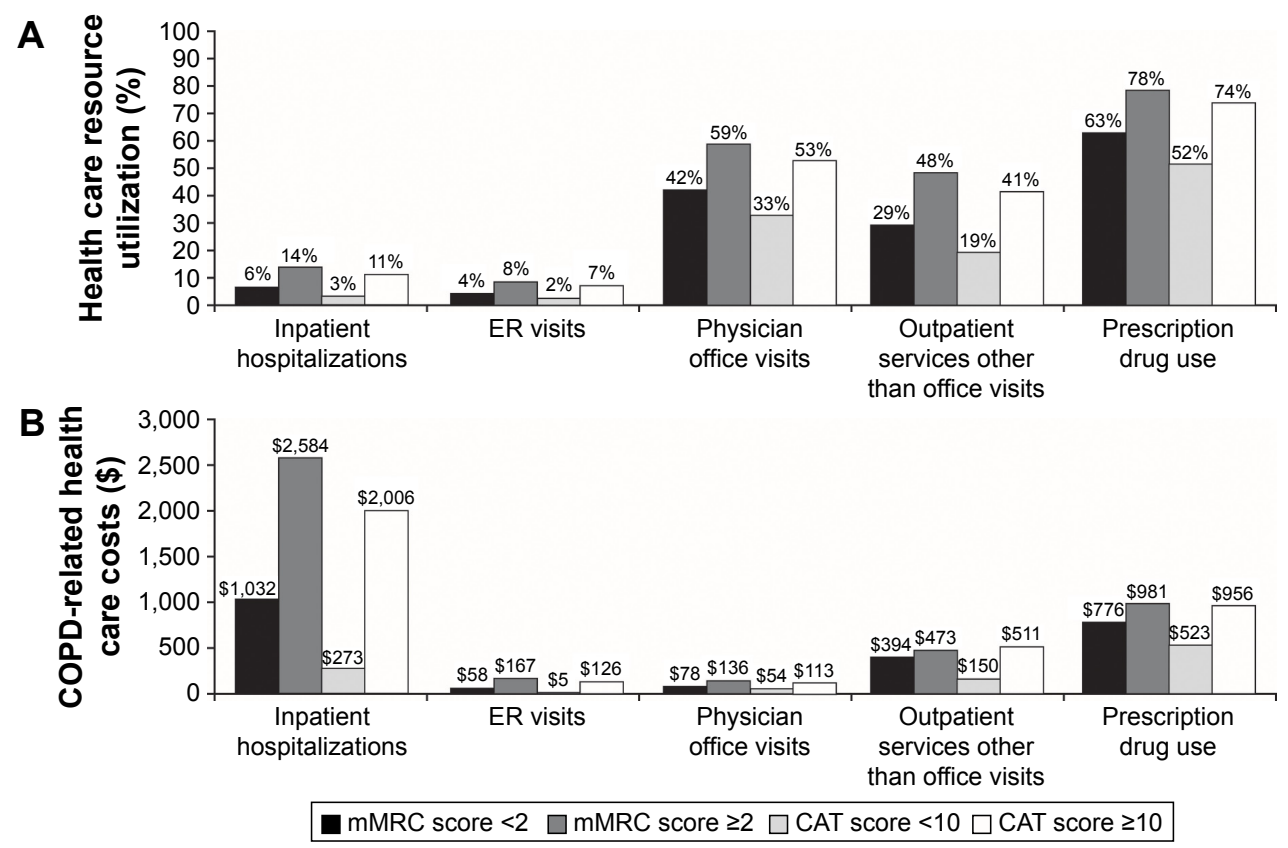

Figure 3 Unadjusted COPD-related: (A) health care resource utilization and (B) health care costs ${ }^{\mathrm{a}}$ in the six-month post-survey period by mMR or CAT COPD symptomatology.

Note: aAll costs are adjusted to 2012 US dollars.

Abbreviations: CAT, COPD Assessment Test; ER, emergency room; mMRC, modified Medical Research Council.

that mMRC and CAT do not distinguish symptom groups precisely in the same way. ${ }^{20}$

Symptoms are the major driving force for physician visits and medication changes. ${ }^{18}$ Therefore, it is to be expected that symptoms are associated with health care resource use and costs. ${ }^{21}$ In keeping with these data from a US health care system, worse dyspnea has been shown to be associated with higher health care resource use in Europe, leading to higher primary care and specialist pulmonary consultation annual rates. In addition, more patients with moderateto-severe dyspnea $(\mathrm{mMRC} \geq 2)$ had at least one ER visit leading to hospitalization compared with patients with no-to-mild dyspnea (mMRC $<2 ; 26.1 \%$ vs $5.8 \% ; P<0.0001$ ). Furthermore, total annual COPD management costs were found to be more than twice as high among patients with moderate-to-severe dyspnea compared with patients with no-to-mild dyspnea ( $€ 4,372$ vs $€ 2,031 ; P<0.0001) .{ }^{19}$ These findings are particularly relevant to payers, as symptoms of COPD are often discounted when coverage decisions are made. Patients with high symptomatology also demonstrated significantly different patient-reported outcome instrument scale/subscale scores compared with those with low symptomatology, indicating that symptomatology impacts on work status, daily activities of living, and productivity.

This study is associated with some limitations. The patient survey results were self-reported and could not be validated; therefore, their accuracy may be subject to selfreport and recall biases. Data regarding health care resource use and costs were based on a large US administrative claims database and are therefore subject to the limitations common to administrative claims analyses. Administrative claims are designed for reimbursement, not research, and may contain undetected diagnostic or treatment coding errors or omissions. The study population was identified from the same US administrative claims database and consisted of individuals and/or their dependents with commercial health insurance plans. Consequently, the results may not be generalizable to patients with COPD who are uninsured, covered by government-sponsored Medicare or Medicaid or who live outside the US. Furthermore, many patients with COPD in the US may have been covered by Medicare or Medicaid, and were not included in the analysis. The strengths of the study included the use of the HIRD, which allowed the researchers to link the survey data with respondents' clinical claims data to allow analysis of health care resource utilization and costs. By integrating multiple data sources, this study capitalized on the strengths of determining COPD symptomatology from the patient's perspective without needing to rely on patient recall of health care resource utilization and cost. This provided a more comprehensive view of the individual patient, making the results more relevant to managed care providers. 
A

High mMRC vs low mMRC

Age $\geq 65$ years vs $40-64$ years

Female vs male

Geographic region vs the North East

Midwest

South

West

PPO vs other plans

Dyspnea claim in pre-period vs no dyspnea claim

Smoking status vs nonsmoker

Former smoker

Current smoker

Employment status vs unemployed person

Part-time worker

Full-time worker

Household income vs $<\$ 50,000$

$\$ 50,000-\$ 99,999$

$\geq \$ 100,000$

Educational status vs $\leq$ high school level

College educated with no degree

At least 2-year degree

Obesity vs normal/underweight

Overweight

Obese

Years since COPD diagnosis

$\mathrm{DCl}$ score

Number of COPD maintenance therapy drug classes

Short-acting beta-agonist use vs no use

Oral corticosteroid prescription use vs no use

Antibiotic use in pre-period vs no use

Home oxygen therapy use in pre-period vs no use

Exacerbation in 12-month pre-period vs no exacerbation

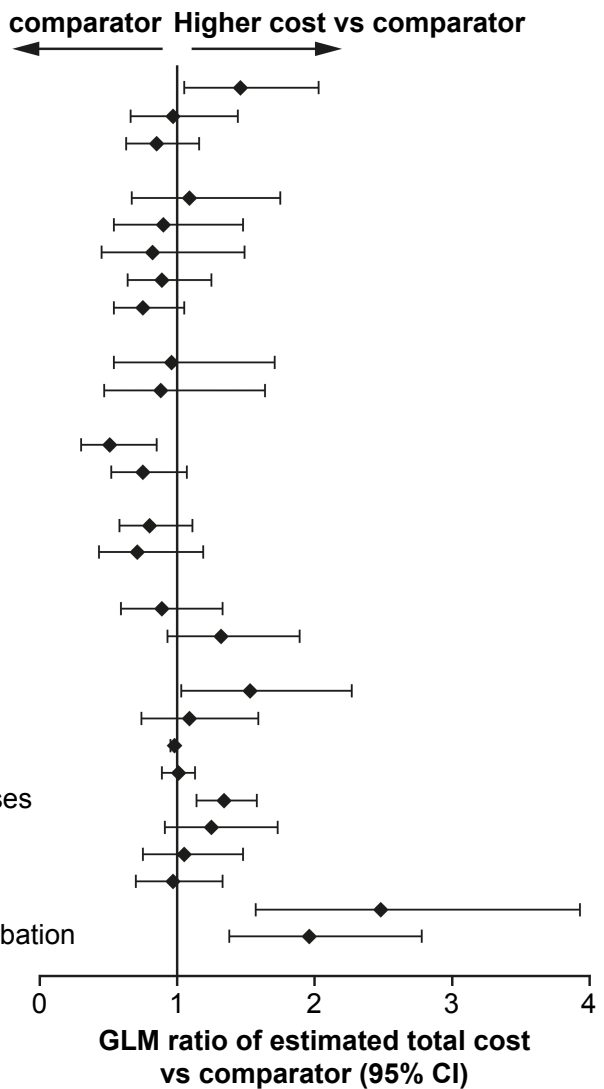

B

CAT score $\geq 10$ vs CAT score $<10$

Age $\geq 65$ years vs $40-64$ years

Female vs male

Geographic region vs the North East

Midwest

South

West

PPO vs other plans

Dyspnea claim in pre-period vs no dyspnea claim

Smoking status vs nonsmoker

Former smoker

Current smoker

Employment status vs unemployed person

Part-time worker

Full-time worker

Household income vs $<\$ 50,000$

$\$ 50,000-\$ 99,999$

$\geq \$ 100,000$

Educational status vs $\leq$ high school level

College educated with no degree

At least 2-year degree

Obesity vs normal/underweight

Overweight

Obese

Years since COPD diagnosis

$\mathrm{DCl}$ score

Number of COPD maintenance therapy drug classes

Short-acting beta-agonist use vs no use

Oral corticosteroid prescription use vs no use

Antibiotic use in pre-period vs no use

Home oxygen therapy use in pre-period vs no use

Exacerbation in 12-month pre-period vs no exacerbation

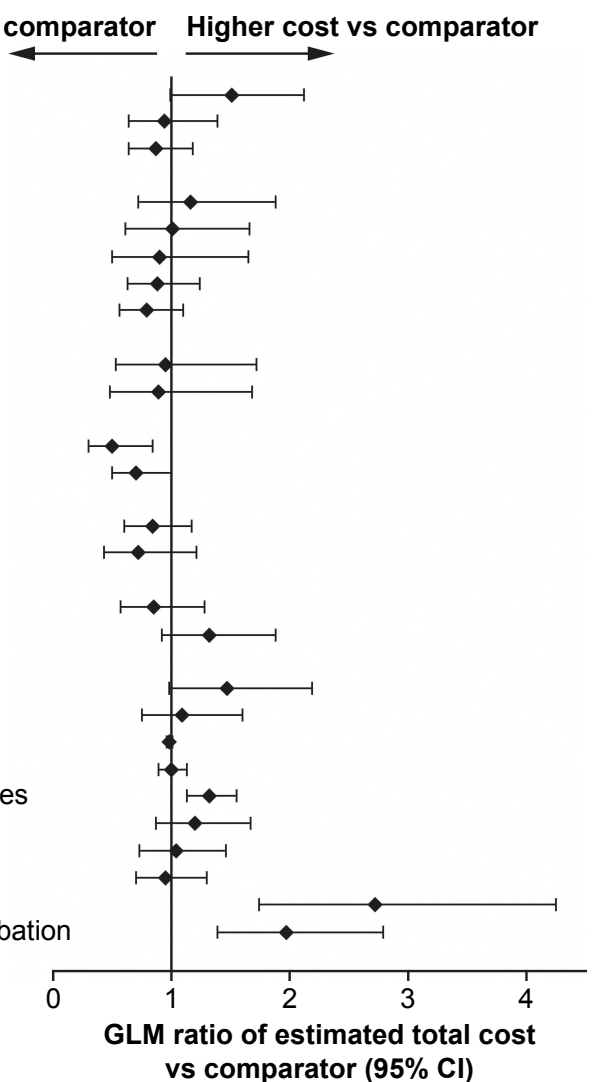

$P$-value

0.025

0.887

0.307

0.733

0.676

0.517

0.518

0.099

0.892

0.683

0.010

0.112

0.177

0.199

0.561

0.125

0.037

0.660

0.082

0.926

$<0.001$

0.175

0.782

0.840

$<0.001$

$<0.001$

$P$-value

0.057

0.760

0.370

0.541

0.972

0.743

0.465

0.164

0.877

0.727

0.009

0.051

0.296

0.215

0.443

0.128

0.061

0.648

0.208

0.983

0.001

0.269

0.838

0.754

$<0.0001$

$<0.001$

Figure 4 Generalized linear model ratios of estimated total COPD-related costs during the 6-month post-survey period of (A) patients with high dyspnea and (B) patients with high CAT COPD symptoms.

Abbreviations: CAT, COPD Assessment Test; Cl, confidence interval; DCl, Deyo-Charlson Comorbidity Index; GLM, generalized linear model; mMRC, modified Medical Research Council; PPO, preferred provider organization. 


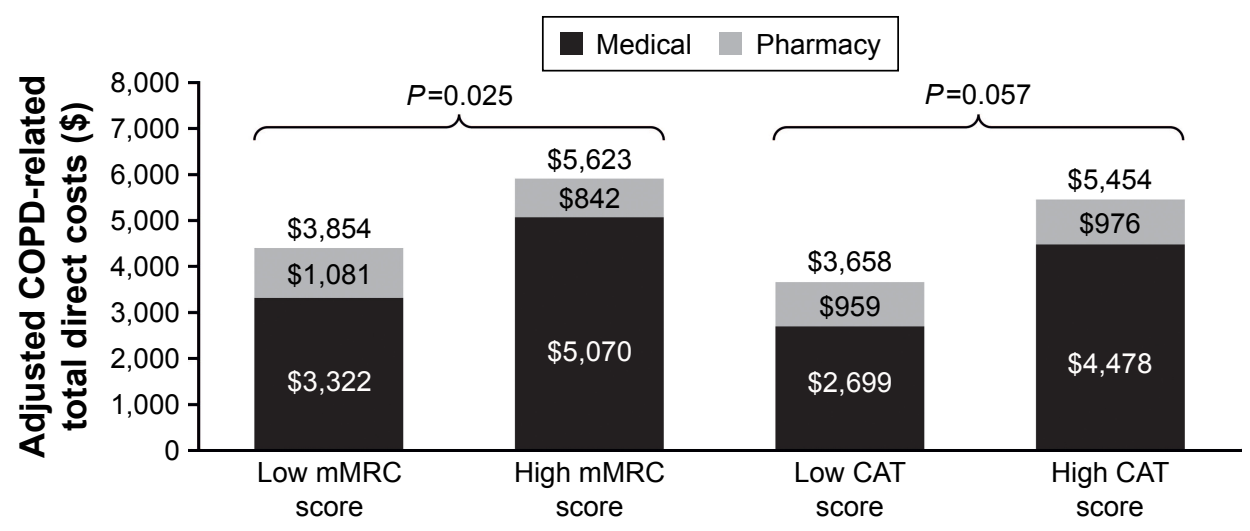

Figure 5 Adjusted COPD-related total direct costs in the six-month post-survey period by mMRC Dyspnea scale symptom category and CAT COPD symptom category. Note: $P$-values were calculated for the differences in total direct costs (ie, medical + pharmacy).

Abbreviations: CAT, COPD Assessment Test; mMRC, modified Medical Research Council.

Future studies could build on the results of this study by following patients and reporting health care resource use and costs over a longer period of time, using a broader set of payer databases, examining change in symptoms and claims over time, and cross-checking symptom and claims data with clinical markers for COPD

\section{Conclusion}

This study demonstrated an association between symptoms and outcomes using managed care claims data integrated with patient survey data. Patients with worse dyspnea and higher health status impairment had more comorbidities, particularly cardiovascular disease, higher risk of exacerbation, and higher health care resource utilization and costs.

\section{Acknowledgments}

Editorial support (in the form of writing assistance, including editing of the initial draft, assembling tables and figures, collating authors' comments, and referencing) was provided by Elizabeth Jameson, PhD, at Fishawack Indicia Ltd, UK, and was funded by GSK. This study HO-11-696 was funded by GSK. The present addresses for the authors Jeetvan Patel and Anand A Dalal are Global Health Economics, Amgen, CA, USA and US Health Economics and Outcomes Research, Novartis Pharmaceuticals, NJ, USA, respectively.

\section{Disclosure}

Jeetvan Patel and Anand A Dalal were employees of GSK at the time of the study and are now employed by Amgen and Novartis Pharmaceuticals, respectively. Judith J Stephenson, Debra Wertz, and Tao Gu are employees of HealthCore, Inc., an independent research organization that received funding from GSK for the conduct of the study. The authors report no other conflicts of interest in this work.

\section{References}

1. Global Initiative for Chronic Obstructive Lung Disease [webpage on the Internet]. Global strategy for the diagnosis, management, and prevention of chronic obstructive pulmonary disease (updated 2016). Available from: http://goldcopd.org/global-strategy-diagnosis-managementprevention-copd-2016. Accessed October 2016.

2. Fitch K, Iwasaki K, Pyenson B, Plauschinat C, Zhang J. Variation in adherence with Global Initiative for Chronic Obstructive Lung Disease (GOLD) drug therapy guidelines: a retrospective actuarial claims data analysis. Curr Med Res Opin. 2011;27(7):1425-1429.

3. Dalal AA, Liu F, Riedel AA. Cost trends among commercially insured and Medicare advantage-insured patients with chronic obstructive pulmonary disease: 2006 through 2009. Int J Chron Obstruct Pulmon Dis. 2011;6:533-542.

4. Dalal AA, Roberts MH, Petersen HV, Blanchette CM, Mapel DW. Comparative cost-effectiveness of a fluticasone-propionate/salmeterol combination versus anticholinergics as initial maintenance therapy for chronic obstructive pulmonary disease. Int J Chron Obstruct Pulmon Dis. 2011;6:13-22.

5. Dalal AA, Shah M, Lunacsek O, Hanania NA. Clinical and economic burden of patients diagnosed with COPD with comorbid cardiovascular disease. Respir Med. 2011;105(10):1516-1522.

6. Hill K, Goldstein RS, Guyatt GH, et al. Prevalence and underdiagnosis of chronic obstructive pulmonary disease among patients at risk in primary care. CMAJ. 2010;182(7):673-678.

7. Jones P, Lareau S, Mahler DA. Measuring the effects of COPD on the patient. Respir Med. 2005;99(suppl B):S11-S18.

8. Manali ED, Lyberopoulos P, Triantafillidou C, et al. MRC chronic Dyspnea Scale: relationships with cardiopulmonary exercise testing and 6-minute walk test in idiopathic pulmonary fibrosis patients: a prospective study. BMC Pulm Med. 2010;10:32.

9. Paladini L, Hodder R, Cecchini I, Bellia V, Incalzi RA. The MRC dyspnoea scale by telephone interview to monitor health status in elderly COPD patients. Respir Med. 2010;104(7):1027-1034.

10. Stenton C. The MRC breathlessness scale. Occup Med (Lond). 2008; 58:226-227.

11. Jones PW, Harding G, Berry P, Wiklund I, Chen WH, Kline Leidy N. Development and first validation of the COPD Assessment Test. Eur Respir J. 2009;34(3):648-654.

12. Reilly MC, Tanner A, Meltzer EO. Work, classroom and activity impairment instruments. Validation studies in allergic rhinitis. Clin Drug Invest. 1996;11:278-288.

13. Ståhl E, Jansson SA, Jonsson AC, Svensson K, Lundbäck B, Andersson F. Health-related quality of life, utility, and productivity outcomes instruments: ease of completion by subjects with COPD. Health Qual Life Outcomes. 2003;1:18. 
14. van der Molen T, Willemse BW, Schokker S, ten Hacken NH, Postma DS, Juniper EF. Development, validity and responsiveness of the Clinical COPD Questionnaire. Health Qual Life Outcomes. 2003; $1: 13$.

15. Ställberg B, Nokela M, Ehrs PO, Hjemdal P, Jonsson EW. Validation of the Clinical COPD Questionnaire (CCQ) in primary care. Health Qual Life Outcomes. 2009;7:26.

16. Parkerson GR, Broadhead WE, Tse CK. The Duke Health Profile. A 17-item measure of health and dysfunction. Med Care. 1990;28(11): 1056-1072.

17. Deyo RA, Cherkin DC, Ciol MA. Adapting a clinical comorbidity index for use with ICD-9-CM administrative databases. J Clin Epidemiol. 1992;45(6):613-619.
18. Rabe KF. Improving dyspnea in chronic obstructive pulmonary disease: optimal treatment strategies. Proc Am Thorac Soc. 2006;3(3): 270-275.

19. Punekar YS, Mullerova H, Small M, et al. Prevalence and burden of dyspnoea among patients with chronic obstructive pulmonary disease in five European countries. Pulmon Ther. 2016;2:59-72.

20. Kim S, Oh J, Kim YI, et al. Differences in classification of COPD group using COPD assessment test (CAT) or modified Medical Research Council (mMRC) dyspnea scores: a cross-sectional analyses. BMC Pulm Med. 2013;13:35.

21. Srivastava K, Thakur D, Sharma S, Punekar YS. Systematic review of humanistic and economic burden of symptomatic chronic obstructive pulmonary disease. Pharmacoeconomics. 2015;33(5):467-488. 


\section{Supplementary materials Methods}

Eligibility criteria

Patients were required to have at least 12 months' continuous enrollment in the health plan prior to the COPD index date, and be currently active, commercially insured health plan members who were eligible to take part in the survey.

\section{Exclusion criteria}

Patients who were on the HealthCore or survey vendor "do not call" lists, or who could not understand/speak English were excluded.

\section{Measures}

The modified Medical Research Council (mMRC) Dyspnea scale grades the severity of dyspnea according to the degree of breathlessness associated with particular tasks. The scale has been validated and used previously for diagnostic evaluation in clinical trials and also to compare categorizations of dyspnea with staging of disease severity. ${ }^{1-3}$

The COPD Assessment Test (CAT) measures health status impairment associated with COPD to determine the impact on a patient's well-being and daily life. ${ }^{4}$ The eightitem unidimensional measure yields scores ranging from 0 to 40 , with higher scores indicating worse COPD-related health status.

The Clinical COPD Questionnaire (CCQ) is a 10-item questionnaire that measures symptom control and functional state in patients with COPD. ${ }^{5,6}$ Three domain scores are obtained from the CCQ; the symptom score is obtained by dividing the sum of the responses to items $1,2,4$, and 5 by 4 ; the functional state score is obtained by dividing the sum of the responses to items $7-10$ by 4 and the mental state score is obtained by dividing the sum of the responses to items 3 and 4 by 2 . Each domain scores ranges from 0 to 6 , with higher scores indicating poorer COPD control.

The Duke Health Profile (DUKE) is a 17-item instrument that assesses an individual's health and feelings. ${ }^{7}$ Eleven subscale scores that range from 0 to 100 are reported. For the physical health, mental health, social health, general health, perceived health and self-esteem scores, 100 indicates the best health status and 0 indicates the worst health status. For the anxiety, depression, anxietydepression, pain and disability scores, the opposite is true and 100 indicates the worst health status and 0 indicates the best health status.

\section{Other survey variables}

Other variables collected at the time of the survey included patient demographics (age, sex, race and ethnicity, education and employment status, and 2010 household income level) and clinical characteristics (smoking status; body mass index; history of COPD diagnosis, including duration and age at COPD diagnosis; whether a breathing or spirometry test had been performed in the previous 6 months; and the presence of cardiovascular risk factors).

\section{Results}

\section{Patient-reported outcomes (survey)}

Patients with high symptomatology were less likely to be working full or part time (mMRC: $37.7 \%$ vs $62.2 \%$; CAT: $49.8 \%$ vs $65.3 \%$ ), and reported significantly more time absent from work (mMRC: $4.78 \%$ vs $1.47 \%, P=0.008$; CAT: $3.0 \%$ vs $0.5 \%, P=0.004)$; on-the-job effectiveness was also significantly reduced compared with those with low symptomatology (mMRC: $26.63 \%$ vs $11.21 \%, P<0.0001$; CAT: $20.2 \%$ vs $2.9 \%, P<0.0001)$. These patients also had reduced work productivity attributed to COPD symptoms (mMRC: $28.9 \%$ vs $11.9 \%, P<0.0001$; CAT: $21.6 \%$ vs $3.5 \%$, $P<0.0001)$ and higher daily activity impairment due to COPD (mMRC: $38.7 \%$ vs $14.9 \%, P<0.0001$; CAT: $27.6 \%$ vs $5.1 \%, P<0.0001)$. Working patients with high symptomatology had significantly higher indirect costs attributable to COPD (mMRC: $\$ 6,394$ vs $\$ 2,671, P<0.0001$; CAT: $\$ 4,802$ vs $\$ 784, P<0.0001)$, CCQ subscale scores, indicating lower COPD control (all $P<0.0001$ ), and DUKE subscale scores, indicating worse health status (all $P<0.0001$ ).

\section{References}

1. Manali ED, Lyberopoulos P, Triantafillidou C, et al. MRC chronic dyspnoea scale: relationships with cardiopulmonary exercise testing and 6-minute walk test in idiopathic pulmonary fibrosis patients: a prospective study. BMC Pulm Med. 2010;10:32.

2. Paladini L, Hodder R, Cecchini I, Bellia V, Incalzi RA. The MRC dyspnoea scale by telephone interview to monitor health status in elderly COPD patients. Respir Med. 2010;104(7):1027-1034.

3. Stenton C. The MRC breathlessness scale. Occup Med (Lond). 2008; 58(3):226-227.

4. Jones PW, Harding G, Berry P, Wiklund I, Chen WH, Kline Leidy N. Development and first validation of the COPD Assessment Test. Eur Respir J. 2009;34(3):648-654.

5. van der Molen T, Willemse BW, Schokker S, ten Hacken NH, Postma DS, Juniper EF. Development, validity and responsiveness of the Clinical COPD Questionnaire. Health Qual Life Outcomes. 2003;1:13.

6. Ställberg B, Nokela M, Ehrs PO, Hjemdal P, Jonsson EW. Validation of the Clinical COPD Questionnaire (CCQ) in primary care. Health Qual Life Outcomes. 2009;7:26.

7. Parkerson GR, Broadhead WE, Tse CK. The Duke Health Profile. A 17-item measure of health and dysfunction. Med Care. 1990;28(11): 1056-1072. 
International Journal of COPD

\section{Publish your work in this journal}

The International Journal of COPD is an international, peer-reviewed journal of therapeutics and pharmacology focusing on concise rapid reporting of clinical studies and reviews in COPD. Special focus is given to the pathophysiological processes underlying the disease, intervention programs, patient focused education, and self management protocols.

This journal is indexed on PubMed Central, MedLine and CAS. The manuscript management system is completely online and includes a very quick and fair peer-review system, which is all easy to use. Visit http://www.dovepress.com/testimonials.php to read real quotes from published authors 